\title{
Awareness About Pictorial Warnings on Tobacco Products Among Tobacco Users - A Questionnaire Study
}

\author{
C.S Yuvashree ${ }^{1}$ and L. Leelavathi ${ }^{2}$
}

${ }^{1}$ Saveetha Dental college and Hospitals, Saveetha Institute of Medical

and Technical Sciences, Saveetha University, Chennai 600077, India

${ }^{2}$ Senior Lecturer, Department of Public Health Dentistry,Saveetha Dental college and Hospitals,

Saveetha Institute of Medical and Technical Sciences, Saveetha University, Chennai 600077, India

\section{ABSTRACT}

The World Health Organization has named tobacco products as one of the greatest causes for several diseases in the world . It has been estimated that 100 million deaths were caused by tobacco and its products in the 20th century. If this situation continues, there will be up to one billion deaths in the 21 st century. The cigarettes packages serve as a cornerstone of tobacco marketing and advertising campaigns. The aim of this study is to assess the awareness about pictorial warnings on tobacco products in tobacco users among outpatients department of Private Dental college.The current study was a questionnaire based and it was conducted in the Saveetha Dental college ,Chennai,India . Nearly 180 tobacco users were recruited from the random sampling method .Only systemically healthy individuals with good mental health participated in the study. The data was collected by a self designed , close ended structure questionnaire which comprised 21 questions and was prepared and given to the participants. The results obtained from the participants were analysed and interpreted .Most of the study participants were males with the mean age of 30-50 years and 89\% of the participants were aware of statutory and pictorial warnings present on the tobacco products. Majority of the subjects (75\%) said pictorial representation on the tobacco packets does not refrain them from i tobacco intake. The pictorial warnings are helpful to some extent but require more strengthening to make pictorial health warnings easier to comprehend to assess the deleterious effects of tobacco by its consumers and general public.

KEY WORDS: TOBACCO, SMOKELESS TOBACCO, PICTORIAL WARNING, AWARENESS, KNOWLEDGE, HARMFUL EFFECTS.

\section{INTRODUCTION}

The World Health Organization (WHO) has named tobacco and its products is the world's greatest cause for several diseases. It has been estimated about 100 million deaths caused by tobacco and its products in

\section{ARTICLE INFORMATION}

*Corresponding Author: leelavathi.sdc@saveetha.com Received 10th June 2020 Accepted after revision 11th August 2020 Print ISSN: 0974-6455 Online ISSN: 2321-4007 CODEN: BBRCBA

Thomson Reuters ISI Web of Science Clarivate Analytics USA and Crossref Indexed Journal

$$
\text { 1) Clarivate }{ }_{\text {Analytics }}
$$

NAAS Journal Score 2020 (4.31) SJIF: 2020 (7.728)

A Society of Science and Nature Publication,

Bhopal India 2020. All rights reserved.

Online Contents Available at: http//www.bbrc.in/

Doi: $h$ ttp://dx.doi.org/10.21786/bbrc/13.7/18 the 20th century(World Health Organization, 2008). If this situation continues, there will be up to one billion deaths in the 21 st century. The cigarettes packages serves as a cornerstone for tobacco marketing and also for the advertising campaigns (Afifi et al., 2020)

In several countries Cigarette packages carry many health warnings. Tobacco has been the first and most perilous killer of humanity in our country(Loyola, 2008). Most of the tobacco stakeholders, caretakers, producers, tobacco farmers, including tobacco consumers, all of them suffer from multiple chronic health diseases (van Mourik et al., 2020). The outcome of tobacco products is decreased life

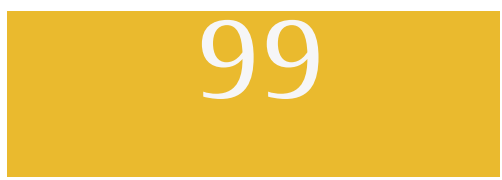


span and a premature miserable death(Kuehnle, 2019). The major consequences of using smoked or smokeless tobacco on the oral cavity starts initially from tobacco stains on the tooth, periodontal diseases, , tooth loss and later leads to life-threatening oral cancer preceded by premalignant red and white lesions.(Ilankizhai and Leelavathi, 2018) $80 \%$ of death occurs mainly due to the consumption of tobacco. India is one among the countries with the highest use of tobacco(T, Thejus and Jayakrishan, 2009). Tobacco packages which are left in public view between users may help in curbing passive smoking as it serves as portable advertisement making nonsmokers aware of deleterious effects of inhaling tobacco smoke(Majumdar, Kumar and Selvaraj, 2017).

Many approaches have been tried to prevent and control the use of tobacco both at individual and community level. (Harini and Leelavathi, 2019) The primary goal of tobacco control policy is to communicate the hazardous effects of tobacco and also the warning labels on tobacco products help in communicating the consequences of tobacco use and also bring about behavioral changes such as quitting or reducing the tobacco consumption(Kuehnle, 2019). Tobacco packaging is not removed and discarded but it is used as a container until the contents have been consumed (Aghi et al., 2012). Therefore, warnings on tobacco packages that combine text and pictures are one of the best and effective methods to increase public awareness of the serious and hazardous health risks of tobacco use and to reduce its consumption (Arora et al., 2012).

The introduction of pictorial health warnings plays the most notable regulatory development in labelling of the products . The pictorial health warnings meant to help users visualize the nature of tobacco-related diseases(Kennedy et al., 2016). In India, the new pictorial health warnings notification was issued on October 15, 2014, but mandatory display of new health warnings covering $85 \%$ of the display area on all tobacco products was notified on September 24, 2015, This made India 3rd among countries with largest pictorial warnings on tobacco products. This initiation of prevention was implemented by the Health Ministry, from April 1 2016, on all forms of tobacco products(Kennedy et al., 2016; Cho et al., 2018). Moreover, in a country like India, where most of the people are illiterate hailing from different cultural and linguistic backgrounds, pictorial warnings along with text can help to break cultural, regional, and language barriers.(Sutton, 1999)

A successful image is that communication being transmitted to the brain is visual; it must tell the viewer the intended story, entirely by visual means of communication(Fong, Hammond and Hitchman, 2009). The visual communication has much more immediate impact than the text because text requires conscious processing and images do not need, which facilitate to empower people to make strong associations between health messages and their perceptions(Shang et al., 2015).
This study was done from the Department of the Public Health Dentistry, in a Saveetha Dental college ,Chennai,India. Since Chennai is a famous city which consists of major population from different states, the public in this area or near to these places coming with dental problems and oral health problems are more prone to get habituated to various forms of tobacco(Patturaja, Leelavathi and Jayalakshmi, 2018; Kuppusamy Sundaram Murthy and Leelavathi, 2019; Shankar and Leelavathi, 2019; Sriram and Leelavathi, 2019).

Figure 1: Depicts the gender of the participants. Blue colour represents males and green colour represents females .Males were more prevalent in tobacco use when compared to females

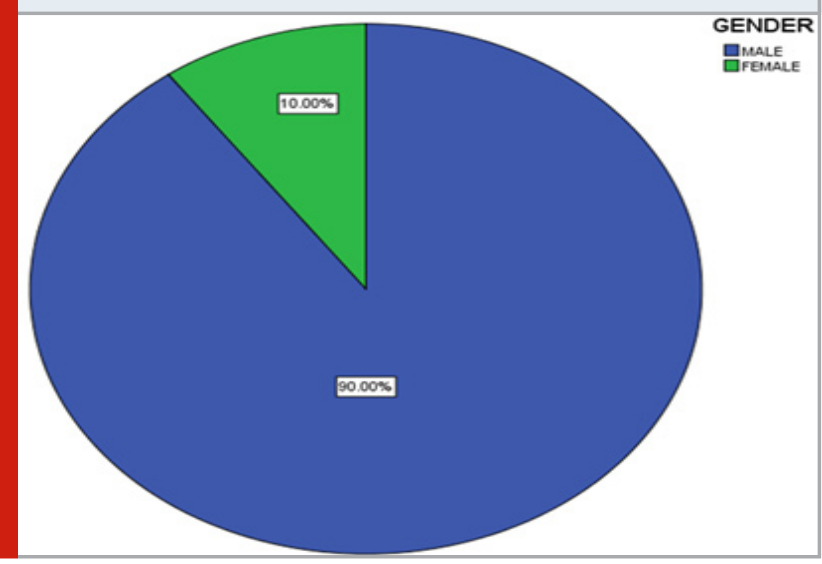

Figure 2: Depicts the age groups of the participants . Pink colour denotes 20-30 years of age. Blue colour denotes 30-50 years of age and Brown colour denotes more than 50 years of age. It is evident that participants between 30-50 years of age were found to be more prevalent

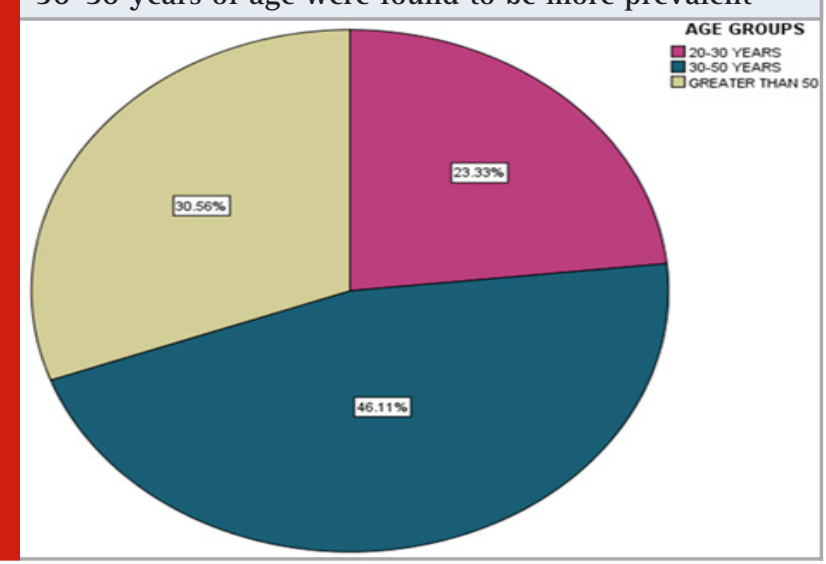

We have successfully completed numerous epidemiological studies for the betterment of our community (Prabakar, John, Arumugham, Kumar and Sakthi, 2018a, 2018b; Prabakar, John, Arumugham, Kumar and Srisakthi, 2018; Vishnu Prasad et al., 2018; Khatri et al., 2019; Manchery et al., 2019; Shenoy, Salam and Varghese, 2019). Hence the aim of this study is to create and assess the awareness about pictorial warnings on tobacco products in tobacco users . 
Figure 3 represents the educational status of the participants. Pink colour denotes educational status up to primary. Orange colour denotes the educational status up to secondary . Grey colour denotes the graduate. The status upto secondary education was found to be more prevalent than other qualifications

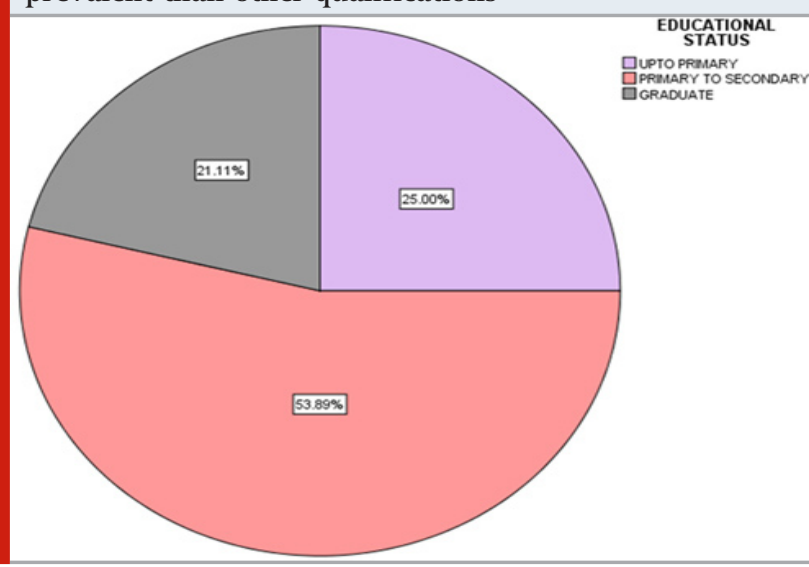

Figure 4 depicts the Awareness of warning signs on tobacco products among subjects . Blue colour denotes yes . Red colour denotes no. It is evident from the pie chart that almost $89 \%$ of the participants were aware of it and only $11 \%$ were unaware of it

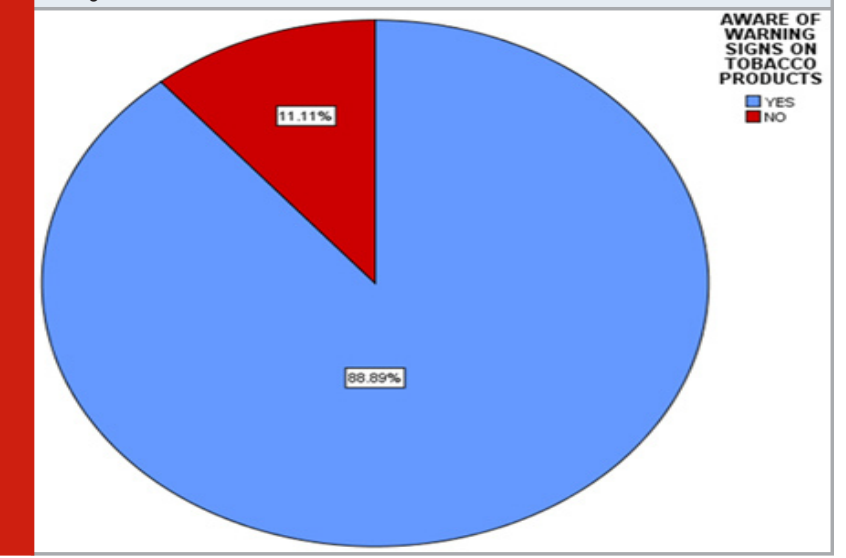

\section{MATERIAL AND METHODS}

It is a questionnaire based study that was conducted in the Saveetha Dental college ,Chennai, India . Nearly180 tobacco user subjects were recruited from the random sampling method. Only systemically healthy individuals with good mental health were participated in this study .Data were collected by the means of self designed, close ended structure questionnaire including 20 questions based on demographic details, knowledge about tobacco products, practices of tobacco habits, Awareness on tobacco products etc. Any Suggestions regarding the improvement in pictorial warning on tobacco products also welcomed from the participants. The data was entered in a methodological manner and it was tabulated in an excel sheet. The tabulated data was imported and compiled for statistical analysis using SPSS software and interpreted.
Figure 5: Represents the participants' knowledge of which side the pictorial warning should be present. Green colour denotes front. Violet colour denotes back. Light Green colour denotes sides . It is evident that nearly $49 \%$ answered pictorial warning should be present in front and $36 \%$ answered for back and the rest answered for sides

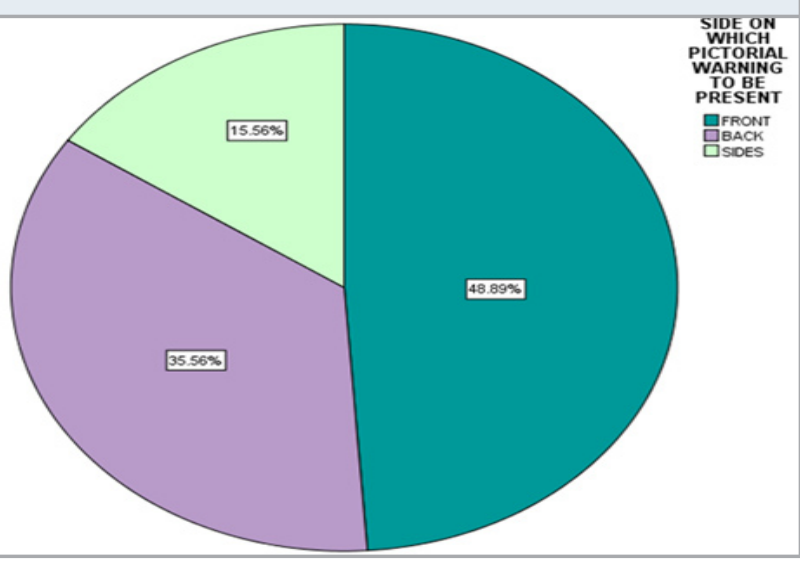

Figure 6: Depicts the association of age and awareness of warning signs on tobacco products among the participants. The $\mathrm{x}$ - axis represents the age groups of the participants. The $\mathrm{y}$ - axis denotes the number of responses. It is evident from the graph that most of the participants were aware about the warning signs on tobacco products in all age groups but some of the participants above 50 years of age were not aware of it .(Pearson chi square test $=51.136$, $\mathrm{P}$ Value $=0.00$, statistically significant)

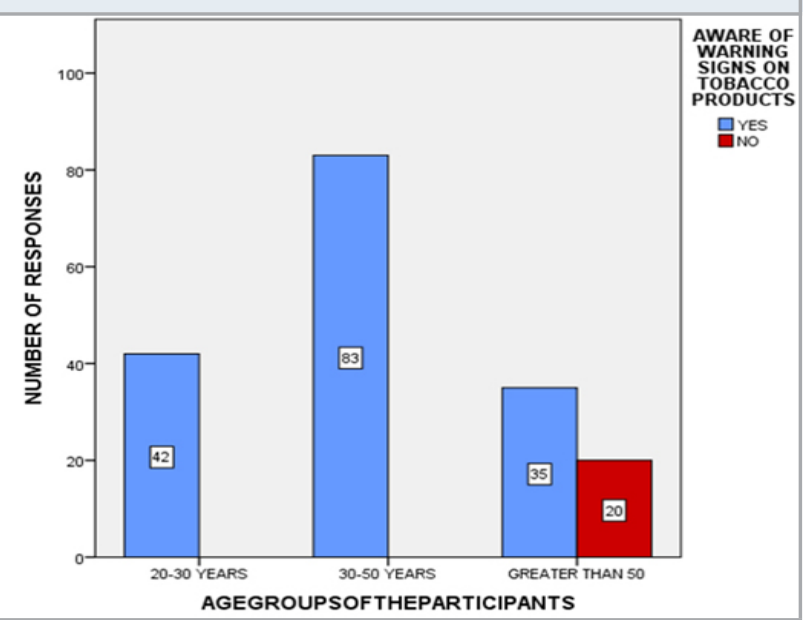

\section{RESULTS AND DISCUSSION}

The use of tobacco products was most commonly found among males between 30-50 years of age [figure 1 and 2]. The educational qualification upto secondary was more prevalent than primary[figure 3]. The usage of tobacco products was more prevalent among daily wages. The most commonly used tobacco products were cigarettes and the habit was found to be more than 5 years with the frequency of 5-10 times a day. The participants were aware about the causative nature of tobacco products [figure 4]. The participants have not taken any steps to 
get rid of the habit but they are willing to participate in tobacco cessation programs and $90 \%$ of the participants were satisfied with the warning signs. Almost 70\% of the participants answered that warning signs on reducing the habit did not cause any impact and did not refrain them from tobacco use and nearly $40 \%$ of the participants stated that pictorial warning of skull and bone had more

Figure 7: Depicts the association of educational status of the participants and steps taken to get rid of the habit by the participants. The $\mathrm{x}$ axis denotes educational status of the participants and $y$ axis denotes number of responses . From the graph it is evident that the participants who are under primary qualification have not taken any steps to get rid of their habits but the participants whose educational qualification is more than secondary have taken some steps to get rid of the habit .(Pearson chi square test $=116.377$, $\mathrm{P}$ Value $=\mathbf{0 . 0 0}$, statistically significant)

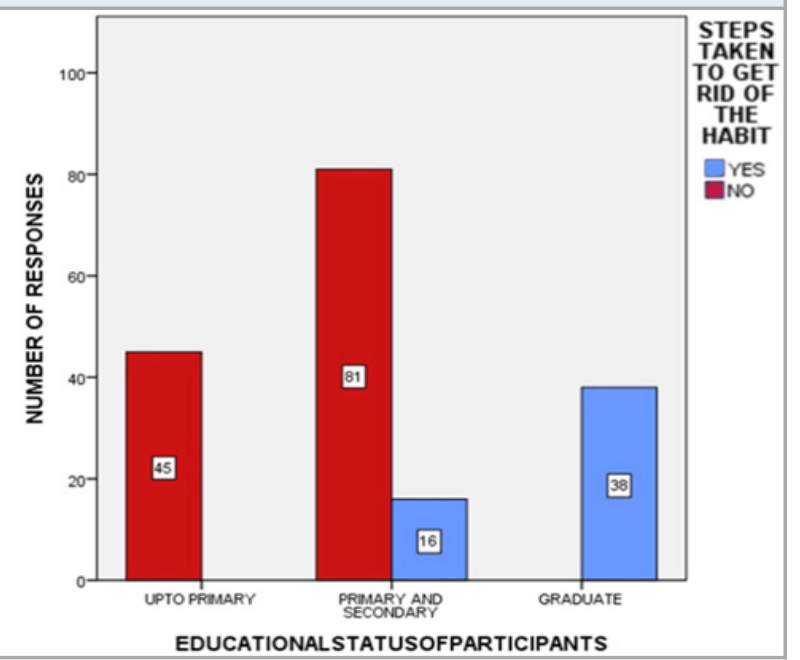

Figure 8: Depicts the association of age groups and tobacco intake refraining due to pictorial warning. The $\mathrm{x}$ axis denotes the age group of participants and $y$ axis denotes the number of responses. Only the participants who are above 50 years of age were refrained from tobacco intake when compared to other age groups (Pearson chi square test $=136.364, \mathrm{P}$ Value $=0.00$, statistically significant)

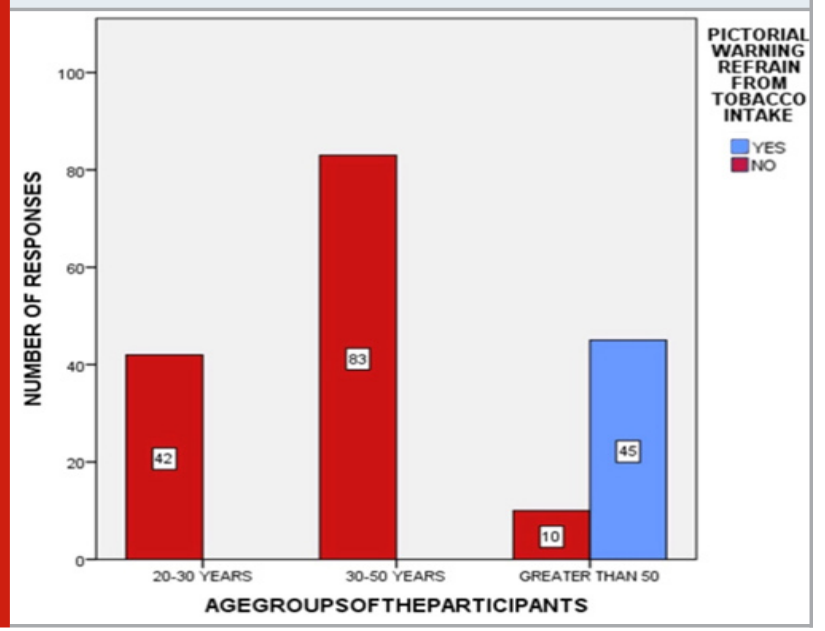

impact. The steps taken by the government were also not sufficient to educate the public even though the pictures which were in the packages were self explanatory and readable and 79\% of the participants answered that the warning text should be made in different languages and the rest said it should not be made in different languages. [Table 1].

Table 1. Practice and Attitude of the participants

\begin{tabular}{|c|c|c|c|}
\hline QUESTIONS & ESPONSES & COUNT & PERCENTAGE \\
\hline $\begin{array}{l}\text { Have you taken } \\
\text { any steps to get } \\
\text { rid of the usage? }\end{array}$ & yes & 126 & $67.4 \%$ \\
\hline $\begin{array}{l}\text { Are you satisfied } \\
\text { with the warning } \\
\text { signs on tobacco } \\
\text { products? }\end{array}$ & yes & 162 & $\begin{array}{l}9.6 \% \\
86.6 \%\end{array}$ \\
\hline $\begin{array}{l}\text { Is there any effect of } \\
\text { warning signs on } \\
\text { reducing the habit? }\end{array}$ & no & $\begin{array}{r}54 \\
126\end{array}$ & $\begin{array}{l}28.9 \% \\
67.4 \%\end{array}$ \\
\hline $\begin{array}{l}\text { Do you think pictorial } \\
\text { warning of the skull } \\
\text { and bone had } \\
\text { more impact? }\end{array}$ & yes & $\begin{array}{l}72 \\
108\end{array}$ & $\begin{array}{l}38.5 \% \\
57.8 \%\end{array}$ \\
\hline $\begin{array}{l}\text { Did pictorial warning } \\
\text { refrain you from } \\
\text { tobacco intake? }\end{array}$ & yes & $\begin{array}{r}45 \\
135\end{array}$ & $\begin{array}{l}24.1 \% \\
72.2 \%\end{array}$ \\
\hline $\begin{array}{l}\text { Are you willing to } \\
\text { participate in the } \\
\text { tobacco cessation } \\
\text { program? }\end{array}$ & yes & 36 & $19.3 \%$ \\
\hline $\begin{array}{l}\text { Do you think steps } \\
\text { laid down by the } \\
\text { government to educate } \\
\text { the public are adequate? }\end{array}$ & $\begin{array}{l}\text { yes } \\
\text { ? no }\end{array}$ & 127 & $67.9 \%$ \\
\hline $\begin{array}{l}\text { Do you think warning } \\
\text { pictures are self } \\
\text { explanatory? }\end{array}$ & $\begin{array}{l}\text { yes } \\
\text { no }\end{array}$ & $\begin{array}{l}131 \\
49\end{array}$ & $\begin{array}{l}70.1 \% \\
26.2 \%\end{array}$ \\
\hline $\begin{array}{l}\text { Is the warning text } \\
\text { readable? }\end{array}$ & $\begin{array}{l}\text { yes } \\
\text { no }\end{array}$ & $\begin{array}{l}92 \\
89\end{array}$ & $\begin{array}{l}49.2 \% \\
47.1 \%\end{array}$ \\
\hline $\begin{array}{l}\text { Do you think warning } \\
\text { text should be made in } \\
\text { different languages? }\end{array}$ & yes & 142 & $75.9 \%$ \\
\hline
\end{tabular}

Almost 49\% answered pictorial warning should be present in front and 36\% answered for back and the rest answered for sides [ figure 5 ] .By correlating the association of age and awareness of warning signs on tobacco products among the participants it is evident that most of the participants were aware about the warning signs on tobacco products in all age groups but more prevalent with the mean age of 30-50 years [figure 6]. By correlating the association of educational status of the participants and steps taken to get rid of the habit by the participants. It is evident that the participants 
who are under primary qualification have not taken any steps to get rid of their habits but the participants who are graduate have taken some steps to get rid of the habit [figure 7]. By correlating the association of age groups and pictorial warning refrain from tobacco intake it was found that pictorial warning did not refrain from the habit and more prevalent in 30-50 years of age [figure 8].

\section{DISCUSSION}

In the present study, 90\% of the participants were found to be males than females with the age group of 30-50 years [ figure 1 and 2 ]. The educational status of the participants was more prevalent in primary - secondary education [ Figure 3] . Most of the tobacco users were found to be daily wages. The prevalence of cigarettes was found to be higher than bidi and smokeless tobacco users. It could be explained by the fact that Chennai was a city and bidi smoking is usually more prevalent in rural areas. Thus the Cigarette smoking was the highest among study participants. The result of the present study was in concordance with the study done by Rahman et al.(Rahman et al., 2015) .Similar results were obtained from the study conducted by karingannanavar et al and chopra et al.(Chopra et al., 2014).

Regarding the time and frequency of usage the tobacco products were used by the participants more than 5 years with the frequency of 5-10 times per day. More than two-third of the respondents were aware of the statutory and pictorial warnings. This finding is comparable to the previous studies done to assess the awareness of health warnings which were found to be $89.9 \%, 74 \%$, and 73.4\% according to study done by Raute et al, Bhat and Kumar and Karibasappa et al .respectively.(Raute, Pednekar and Gupta, 2009; Oswal et al., 2011). The harmful effect of tobacco products, it was found that the bidi smoking is more harmful as compared to cigarettes. People believe that due to the presence of filters and more refined forms of tobacco, cigarettes have less harmful effect(T, Thejus and Jayakrishan, 2009).

Nearly $30 \%$ of the participants took steps to get rid of the habits even though they are not satisfied with the warning signs on tobacco products. About 70\% respondents could understand pictorial warnings but found them ineffective in shunning the habit and also a disappointing and realistic fact is that the pictorial warning of skull and bone did not have any impact and had a little refrain on the users. The results of our study were found to be in concordance with the study conducted in Mumbai by Oswal et al, Arora et al ,Chopra et al. which suggest that pictorial warnings that exist on tobacco packs are perceived to be ineffective by the Indian population.(Aghi et al., 2012)(Oswal et al., 2011). A very high percentage $(80 \%)$ of people indulge in tobacco habit wishes by participating in anti-tobacco and tobacco cessation programs. It shows that if we plan to organise some anti-tobacco or cessation programs in future, it will have great success. our responsibility regarding anti-tobacco programs should not be just limited to adding pictures and text warnings on tobacco products. (Ilakkuvan et al., 2018).

In the current study the steps laid down by the government to educate the public were not adequate . Continued use of ineffective warning pictures and warning signs on tobacco products add on light to the missed opportunities as the government failed to effectively and efficiently utilise this strategy to amplify knowledge about the tobacco health hazards among the public, in addition to another educational interventions, for example anti-tobacco advertising employed by the ministry of health and family welfare in India(Vogel, 2011). It was found that pictorial warnings were self explanatory and readable. The whole objective is to communicate not only with tobacco users but also with prospective quitters and probable initiators.(Sternberg, 1988) 79\% suggested that the warning text can be made in different languages. [ Table 1]. The text and warning signs should be made in the front page of the package of the products [ figure 5] .

By correlating the association of age and awareness of warning signs on tobacco products among the participants.. It is evident that most of the participants were aware about the warning signs on tobacco products in all age groups but higher with the mean age of 3050 years [figure 6]. By correlating the association of educational status of the participants and steps taken to get rid of the habit by the participants. It is evident that the participants who are under primary qualification have not taken any steps to get rid of their habits but the participants whose educational qualification is more than secondary have taken some steps to get rid of the habit [figure 7]. By correlating the association of age groups and pictorial warning refrain from tobacco intake it was found that pictorial warning did not refrain from the habit and more prevalent in 30-50 years of age .

This cross sectional study limits the assessment of reduction of tobacco habits among study samples. Second, this study is single hospital based rather than being population based which hinders the better understanding of the problem. Keeping all these limitations in mind we should plan some more studies on varied samples in future.

\section{CONCLUSION}

The pictorial warnings are helpful to some extent but require more strengthening to make pictorial health warnings easier to comprehend to assess the deleterious effects of tobacco by its consumers and general public. The visual communication has much more immediate impact than the text because text requires conscious processing and images do not, which facilitate to empower people to make strong associations between health messages and their perceptions.

\section{ACKNOWLEDGEMENTS}

The authors would like to acknowledge the help and 
support rendered by the Department of Public Health Dentistry Of Saveetha Dental College and Hospitals, SIIMATS for their constant assistance for the research.

Conflict of the Study: Authors declare no potential conflict of interest.

\section{REFERENCES}

Afifi, R. et al. (2020) 'Evidence from the Lebanon Global School-based Student Health Survey on midwakh tobacco smoking in school students: a harbinger of the next global tobacco pandemic?', Eastern Mediterranean health journal $=$ La revue de sante de la Mediterranee orientale $=$ al-Majallah al-sihhiyah al-sharq almutawassit, 26(1), pp. 116-121.

Aghi, M. et al. (2012) 'Pictorial warnings on tobacco products at the point of sale in India: Figure 1', Tobacco Control, pp. 450-451. doi: 10.1136/tobaccocontrol2011-050035.

Arora, M. et al. (2012) 'Ineffective pictorial health warnings on tobacco products: Lessons learnt from India', Indian Journal of Public Health, p. 61. doi: 10.4103/0019-557x.96978.

Chopra, A. et al. (2014) 'Communicating tobacco health risks: How effective are the warning labels on tobacco products?', Nigerian medical journal: journal of the Nigeria Medical Association, 55(5), pp. 411-416.

Cho, Y. J. et al. (2018) 'Does Adding Information on Toxic Constituents to Cigarette Pack Warnings Increase Smokers' Perceptions About the Health Risks of Smoking? A Longitudinal Study in Australia, Canada, Mexico, and the United States', Health education \& behavior: the official publication of the Society for Public Health Education, 45(1), pp. 32-42.

Fong, G. T., Hammond, D. and Hitchman, S. C. (2009) 'The impact of pictures on the effectiveness of tobacco warnings', Bulletin of the World Health Organization, 87(8), pp. 640-643.

Harini, G. and Leelavathi, L. (2019) 'Nicotine Replacement Therapy for Smoking Cessation-An Overview', Indian Journal of Public Health Research \& Development, p. 3588. doi: 10.5958/0976-5506.2019.04144.5.

Ilakkuvan, V. et al. (2018) 'Antitobacco Attitude Survey’, PsycTESTS Dataset. doi: 10.1037/t65373-000.

Ilankizhai, R. J. and Leelavathi, L. (2018) 'Comparison of oral microbiota among smokers and non-smokers-A pilot study', Drug Invention Today, 10. Available at: http://search.ebscohost.com/login.aspx?direct=true\&tp rofile $=$ ehostCtscope $=$ site\&tauthtype $=$ crawler\&tjrnl $=097$ 57619\&AN=133549238cth=EgXolQhE1tn 1yOg85LGLq wGkGP0R1xs9uPyTWyDoZkmCJLN1sY1C\%2FPYTo1z AX6Id6\%2Bps6doHM\%2BgN6vULwg\%2BfwQ\%3D\%3 DEtcrl=c.

Kennedy, R. D. et al. (2016) 'Educating smokers about the risk of blindness - insights to improve tobacco product health warning labels', Tobacco induced diseases, 14, p. 30.

Khatri, S. G. et al. (2019) 'Retention of moisture-tolerant fluoride-releasing sealant and amorphous calcium phosphate-containing sealant in 6-9-year-old children: A randomized controlled trial', Journal of the Indian Society of Pedodontics and Preventive Dentistry, 37(1), pp. 92-98.

Kuehnle, D. (2019) 'How effective are pictorial warnings on tobacco products? New evidence on smoking behaviour using Australian panel data', Journal of Health Economics, p. 102215. doi: 10.1016/j. jhealeco.2019.06.002.

Kuppusamy Sundaram Murthy, S. P. and Leelavathi, L. (2019) 'Comparison of Coca Cola and Diet Coca Cola on the Surface Enamel Roughness', Indian Journal of Public Health Research \& Development, 10(11). Available at: https://bit.ly/38Wm8EB

Loyola, E. (2008) 'Linking Global Youth Tobacco Survey (GYTS) Data to the WHO Framework Convention on Tobacco Control', Preventive Medicine, p. S1. doi: 10.1016/j.ypmed.2008.08.004.

Majumdar, A., Kumar, S. and Selvaraj, R. (2017) 'Awareness of health warnings and factors predicting awareness and perceived effectiveness of pictorial health warnings on tobacco products among adults in rural Puducherry, India', Journal of Education and Health Promotion, p. 23. doi: 10.4103/jehp.jehp_72_15.

Manchery, N. et al. (2019) 'Remineralization potential of dentifrice containing nanohydroxyapatite on artificial carious lesions of enamel: A comparative in vitro study', Dental research journal, 16(5), p. 310.

van Mourik, D.-J. A. et al. (2020) 'Differences in smokers' awareness of the health risks of smoking before and after introducing pictorial tobacco health warnings: findings from the 2012-2017 international tobacco control (ITC) Netherlands surveys', BMC public health, 20(1), p. 512.

Oswal, K. C. et al. (2011) 'Are current tobacco pictorial warnings in India effective?', Asian Pacific journal of cancer prevention: APJCP, 12(1), pp. 121-124.

Patturaja, K., Leelavathi, L. and Jayalakshmi, S. (2018) 'Choice of Rotary Instrument Usage among Endodontists--A Questionnaire Study', Biomedical and Pharmacology Journal, 11, p. 851+.

Prabakar, J., John, J., Arumugham, I. M., Kumar, R. P. and Srisakthi, D. (2018) 'Comparative Evaluation of Retention, Cariostatic Effect and Discoloration of Conventional and Hydrophilic Sealants - A Single Blinded Randomized Split Mouth Clinical Trial', Contemporary clinical dentistry, 9(Suppl 2), pp. S233S239.

Prabakar, J., John, J., Arumugham, I. M., Kumar, R. P. and Sakthi, D. S. (2018a) 'Comparative Evaluation of the Viscosity and Length of Resin Tags of Conventional 
and Hydrophilic Pit and Fissure Sealants on Permanent Molars: An Study', Contemporary clinical dentistry, 9(3), pp. 388-394.

Prabakar, J., John, J., Arumugham, I. M., Kumar, R. P. and Sakthi, D. S. (2018b) 'Comparing the Effectiveness of Probiotic, Green Tea, and Chlorhexidine- and Fluoride-containing Dentifrices on Oral Microbial Flora: A Double-blind, Randomized Clinical Trial', Contemporary clinical dentistry, 9(4), pp. 560-569.

Rahman, M. M. et al. (2015) 'Effectiveness of pictorial health warning on cigarette packages: A cross-sectional study in Sarawak, Malaysia', Malaysian family physician : the official journal of the Academy of Family Physicians of Malaysia, 10(3), pp. 19-26.

Raute, L. J., Pednekar, M. S. and Gupta, P. C. (2009) 'Pictorial Health Warnings on Cigarette Packs: A Population Based Study Findings from India', Tobacco Use Insights, p. TUI.S2751. doi: 10.4137/tui.s2751.

Shang, C. et al. (2015) 'Weight control belief and its impact on the effectiveness of tobacco control policies on quit attempts: findings from the ITC 4 Country Survey', Tobacco Control, pp. iii41-iii47. doi: 10.1136/ tobaccocontrol-2014-051886.

Shankar, S. and Leelavathi, L. (2019) 'Assessment of Depression and Attitude Towards Missing Teeth Replacement in Geriatric Patients', Indian Journal of Public Health Research \& Development, 10(11). Available at: https://bit.ly/32fFymB

Shenoy, R. P., Salam, T. A. A. and Varghese, S. (2019) 'Prevalence and Clinical Parameters of Cervical
Abrasion as a Function of Population, Age, Gender, and Toothbrushing Habits: A Systematic Review', World Journal of Dentistry, 10(6), pp. 470-480.

Sriram, N. and Leelavathi, L. (2019) 'Knowledge, Attitude and Practice Towards Evidence based Practice among Medical and Dental Students', Indian Journal of Public Health Research \& Development, p. 3716. doi: 10.5958/0976-5506.2019.04168.8.

Sternberg, K. (1988) ‘Antitobacco Project Begins', JAMA: The Journal of the American Medical Association, p. 1836. doi: 10.1001/jama.1988.03410130018006.

Sutton, S. R. (1999) 'How accurate are smokers' perceptions of risk?', Health, Risk \& Society, pp. 223-230. doi: 10.1080/13698579908407020.

T, T., Thejus, T. and Jayakrishan, T. (2009) 'Pictorial warnings on tobacco products: how delayed and diluted in India?', Indian Journal of Medical Ethics. doi: 10.20529/ijme.2009.033.

Vishnu Prasad, S. et al. (2018) 'Report on oral health status and treatment needs of 5-15 years old children with sensory deficits in Chennai, India', Special care in dentistry: official publication of the American Association of Hospital Dentists, the Academy of Dentistry for the Handicapped, and the American Society for Geriatric Dentistry, 38(1), pp. 58-59.

Vogel, L. (2011) 'Antitobacco programs underfunded, WHO says', Canadian Medical Association Journal, pp. E769-E770. doi: 10.1503/cmaj.109-3946.

World Health Organization (2008) WHO Report on the Global Tobacco Epidemic, 2008: The MPOWER Package. World Health Organization. 